\title{
National survey of blindness and visual impairment in Guatemala, 2015
}

\section{Pesquisa nacional sobre cegueira e deficiência visual na Guatemala, 2015}

\author{
Gloria Marina Serrano Chávez', Ana Rafaela Salazar de Barrios², Oscar Leonel Figueroa Pojoy?, \\ Aida del Rosario Monzón Herrera de Reyes ${ }^{3}$, Mariano Yee Melgar ${ }^{4}$, Juan Francisco Yee Melgar ${ }^{4}$, Mario de León Régil ${ }^{5}$, \\ Carlos Alberto Mendoza Hernandez ${ }^{6}$, Victor Alfonso Miranda Chanquin', Evelyn Diaz', Van C. Lansingh 8,9,10, \\ Hans Limburg" ${ }^{11}$ Juan Carlos Silva, ${ }^{12}$ João M. Furtado' ${ }^{13}$ \\ 1. Ministerio de Salud Pública y Asistencia Social de Guatemala, Guatemala. \\ 2. Unidad Nacional de Oftalmología, Guatemala \\ 3. Asociación Instituto Panamericano Contra la Ceguera, Guatemala. \\ 4. Visualiza, Guatemala. \\ 5. Benemérito Comité Pro Ciegos y Sordos de Guatemala, Guatemala. \\ 6. Brigada Médica Cubana, Havana, Cuba. \\ 7. Centro Oftalmológico Digar SRL, Republica Dominicana. \\ 8. Instituto Mexicano de Oftalmología, Querétaro, Mexico. \\ 9. Help Me See, United States of America. \\ 10. International Council of Ophthalmology, United States of America. \\ 11. Health Information Services, Grootebroek, Netherlands. \\ 12. Organización Panamericana de la Salud (OPAS), Bogotá, Colombia. \\ 13. Divisão de Oftalmologia, Faculdade de Medicina de Ribeirão Preto, Universidade de São Paulo, Ribeirão Preto, SP, Brazil.
}

\begin{abstract}
Purpose: To estimate the prevalence of blindness and visual impairment in older adults living in Guatemala. Methods: Participants $\geq 50$ years of age were selected using random cluster sampling and evaluated using the Rapid Assessment of Avoidable Blindness method. Visual acuity was measured, and the lens was examined. If presenting visual acuity was $<20 / 60$, it was also tested with a pinhole and fundoscopy was performed. Blindness and visual impairment were classified as moderate visual impairment (presenting visual acuity $<20 / 60$ to 20/200), severe visual impairment (presenting visual acuity $<20 / 200$ to $20 / 400$ ), or blindness (presenting visual acuity $<20 / 400$ ). The primary cause of blindness or visual impairment in each eye was determined, and if the cause was cataracts, the barriers to treatment were assessed. Results: The study included 3,850 people $\geq 50$ years of age, of whom 3,760 (97.7\%) were examined. The age- and sex-adjusted prevalence of blindness was $2.9 \%$ (95\% confidence interval, $2.0 \%-3.8 \%$ ), while $5.2 \%$
\end{abstract}

Submitted for publication: October 10, 2017

Accepted for publication: February 9, 2018

Funding: This study was supported by the International Agency for the Prevention of Blindness, ORBIS International, CBM, and the Ministry of Health of Guatemala. Disclosure of potential conflicts of interest: None of the authors have any potential conflict of interest to disclose.

Corresponding author: João M. Furtado

E-mail: furtadojm@fmrp.usp.br
(4.0\%-6.4\%) presented with severe visual impairment, and $27.6 \%$ (23.3\%-32.0\%) presented with moderate visual impairment. Cataracts were the leading cause of blindness (77.6\%), followed by other posterior segment diseases $(6.0 \%)$. Cataracts caused $79.4 \%$ of cases of severe visual impairment, while uncorrected refractive errors caused $67.9 \%$ of cases of moderate visual impairment. Following cataract surgery, $75 \%$ of participants had a presenting visual acuity of 20/200 or better, and in $19.0 \%$ of participants, visual acuity was not better than 20/200 with correction. Cost was the main barrier to cataract surgery (56.7\%). Conclusions: The prevalence of blindness in older adults is higher in Guatemala than in most Central American countries. Most cases of blindness and visual impairment were either preventable or treatable. Increased availability of affordable, high-quality cataract treatment would have a substantial impact on blindness prevention.

Keywords: Blindness/epidemiology; Prevalence; Vision, low/ epidemiology; Cataract extraction

RESUMO | Objetivo: Estimar a prevalência de cegueira e deficiência visual em idosos que vivem na Guatemala. Métodos: Indivíduos com idade $\geq 50$ anos foram selecionados por amostragem aleatória por conglomerados, e os participantes do estudo foram avaliados pelo método de Avaliação Rápida da Cegueira Evitável. A acuidade visual foi medida e o cristalino foi examinado. Se a acuidade visual apresentada fosse $<20 / 60$, então também foi testada com um buraco estenopeico e a fundoscopia realizada. 
A cegueira e a deficiência visual foram classificadas como deficiência visual moderada com acuidade visual $<20 / 60-20 / 200$; deficiência visual grave com acuidade visual <20/200-20/400; ou cegueira com acuidade visual $<20 / 400$. A principal causa de cegueira ou deficiência visual em cada olho foi determinada, e naqueles com catarata, as barreiras ao tratamento foram avaliadas. Resultados: $\mathrm{O}$ estudo incluiu 3.850 pessoas com $\geq 50$ anos de idade; 3.760 (97,7\%) foram examinadas. A prevalência de cegueira ajustada à idade e ao sexo foi de $2,9 \%$ (intervalo de confiança de 95\%, 2,0-3,8\%), 5,2\% (4,0-6,4\%) deficiência visual grave e $27,6 \%$ (23,3-32,0\%) deficiência visual moderada. A catarata foi a principal de cegueira $(77,6 \%)$, seguida de outras doenças do segmento posterior $(6,0 \%)$. Catarata causada por $79,4 \%$ de deficiência visual grave, enquanto erros refrativos não corrigidos causaram 67,9\% de deficiência visual moderada. Após a cirurgia de catarata, 75\% dos participantes tiveram uma acuidade de 20/200, ou melhor, e 19,0\% a deficiência visual não foi melhor do que 20/200 com a correção. O custo foi a principal barreira à cirurgia de catarata (56.7\%). Conclusões: A prevalência de cegueira em idosos é maior na Guatemala do que na maioria dos outros países da América Central. A maioria dos casos de cegueira e deficiência visual era evitável ou tratável. O aumento da disponibilidade de tratamento de catarata a preços acessíveis e de alta qualidade teria um impacto substancial na prevenção da cegueira.

Descritores: Cegueira/epidemiologia; Prevalência; Baixa visão/ epidemiologia; Extração de catarata

\section{INTRODUCTION}

Despite the efforts of the VISION 2020 Initiative, more than 2 million people in the Latin American and Caribbean region are blind, and 14 million have moderate or severe visual impairment ${ }^{(1,2)}$. Most cases are treatable. Recent nationwide population-based studies of blindness and visual impairment conducted in Latin America using the Rapid Assessment of Avoidable Blindness (RAAB) methodology ${ }^{(3)}$ found that cataracts were the primary cause of blindness and uncorrected refractive errors were the leading cause of moderate visual impairment.

The Republic of Guatemala is a Central American country of 108,889 km² bordered by Mexico, Belize, Honduras, El Salvador, the Pacific Ocean, and the Caribbean $\mathrm{Sea}^{(4)}$. The country is divided into eight regions and 22 departments. The estimated total population in 2015 was $16,342,897$, with about one-third living in the capital, Guatemala City ${ }^{(5)}$. Approximately $13 \%$ of the population is $\geq 50$ years of age ${ }^{(6)}$, which is among the lowest percentage for this age group in Latin America. The World Bank classifies Guatemala as a lower-middle-income country. It is one of the poorest countries in Latin America, with $11.5 \%$ of its population living under the poverty line of USD 1.90/day and large urban and rural inequalities. The country has an estimated 1.3 ophthalmologists per 100,000 people, and most opthalmologists practice in Guatemala City. The average for Latin America is 5.2 ophthalmologists per 100,000 people $^{(7)}$.

Little is known about the causes of eye disease in Guatemala. The only population-based data are from 2004 and were collected in only four departments ${ }^{(8)}$. Trachoma and trachomatous trichiasis are endemic ${ }^{(9)}$, but onchocerciasis was recently considered eliminated as a result of a large ivermectin distribution program carried out in previously endemic areas ${ }^{(10)}$. Using the RAAB methodology $y^{(11)}$, we investigated the prevalence and causes of blindness and visual impairment in Guatemala in people $\geq 50$ years of age. Cataract surgical coverage, visual outcomes after cataract surgery, and barriers to cataract surgical services were assessed.

\section{METHODS}

The entire country was selected as the survey area. The 2012 national census estimated that the total population at the time of the study was $14,938,645$ people, with $12.4 \%(1,852,392) \geq 50$ years of age. Informed consent was obtained from eligible subjects who agreed to participate. The study was performed following the ethical guidelines of the Declaration of Helsinki. All individuals needing medical assistance were either treated or referred to the nearest medical unit. As there have been no previous nationwide population-based studies of blindness in Guatemala, the prevalence of blindness in participants $\geq 50$ years of age was estimated as $2.6 \%$ based on data from studies in neighboring Central American countries. For an estimated prevalence of $2.6 \%$ and a study noncompliance rate of $10 \%$, a sample size of 3,850 was calculated to be powerful enough to detect a variation of $25 \%$ around the estimated prevalence with 95\% probability. The Instituto Nacional de Estadística de Guatemala provided the list of 15,511 census enumeration areas (EAs) and their population used in the 2012 national census, which was used as a sampling frame. Seventy-seven EAs were selected by systematic sampling using the RAAB software module, which allows a random selection of clusters. EAs with larger populations had higher odds of selection; probability was proportional to size. In each of the randomly selected EAs, 50 residents $\geq 50$ years of age were selected for ocular examination by compact segment sampling.

Four data collection teams, each including a third-year ophthalmology resident or senior ophthalmologist, an 
ophthalmic assistant, and a local guide, conducted the study and were trained by a certified RAAB trainer (ED) just before the fieldwork. Prior to data collection, interobserver variations in measurement of visual acuity (VA), lens evaluation, and determination of the primary cause of a presenting visual acuity (PVA) $<20 / 40$, were assessed to ensure standardization and quality of the ocular examination. All teams achieved a good kappa $\geq 0.60$. The fieldwork was conducted between June and December 2015.

The survey protocol used the RAAB methodology (RAAB ver. 5), and a Spanish version of the standard RAAB survey form was completed for each eligible subject. VA was measured in daylight in the participant's residence with a Snellen tumbling "E" chart at distances of 20 and 10 feet. The VA of each eye was measured, and a pinhole was used when the PVA was $<20 / 60$. The presence of lens opacification was assessed with distant direct ophthalmoscopy (red reflex) with the participant in a (semi) dark room. Lens status was scored as normal (no or minimal opacification), obvious opacification, aphakia, or pseudophakia with or without posterior capsule opacification (PCO). When needed, direct ophthalmoscopy was conducted after pupil dilatation. Blindness and PVA in the eye with better vision were classified as follows: PVAs from $<20 / 60$ to 20/200 were classified as moderate visual impairment (MVl), and those from $<20 / 200$ to 20/400) were classified as severe visual impairment $(\mathrm{SVl})$. A PVA of $<20 / 400$ was scored as blindness. The primary cause of blindness or visual impairment was assessed in each eye. If there were two or more causes and it could not be determined which was the primary cause of vision loss, then, following the World Health Organization (WHO) guideline, the cause that was easiest to treat or to prevent was chosen ${ }^{(11)}$.

Cataract surgery coverage (CSC) was defined as the number of eyes or individuals with operable cataract divided by the number of eyes or individuals with pseudophakia, aphakia, or operable cataracts and was reported as a percentage ${ }^{(12)}$. Visual outcomes after cataract surgery were rated as good (PVA $\geq 20 / 60$ ), borderline (PVA <20/60-20/200), or poor (PVA <20/200). The causes of poor visual outcome included selection, which entailed participants presenting with vision-impairing conditions other than cataracts, such as glaucoma or age-related macular degeneration; surgical (e.g., vitreous loss); optical (e.g., postoperative astigmatism); or late surgical complications (e.g., retinal detachment or PCO). In those with the best corrected visual acuity (BCVA)
$<20 / 200$ and operable cataracts, the barriers to cataract services were assessed. The reasons included "need not felt," "fear of surgery or a poor result," "cannot afford surgery," "treatment denied by health care provider," "unaware that treatment is possible," and "no access to treatment.”

\section{Statistical analysis}

The overall and age- and sex-adjusted prevalence of blindness and visual impairment were calculated with 95\% confidence intervals (Cls) for cluster sampling. The RAAB software program was used for data entry and automatic data analysis. The data were double-entered into RAAB software and checked for consistency and potential entry errors.

\section{RESULTS}

The study included 3,850 people $\geq 50$ years of age. Of the 3,760 (97.7\%) who were evaluated, 1,527 (40.61\%) were men and 2,233 (59.38\%) were women. Thirty-one subjects $(0.8 \%)$ could not be contacted, 49 (1.3\%) refused to participate, and $10(0.3 \%)$ were not capable of participation. The age- and sex-adjusted prevalence of blindness (Table 1) was 2.9\% (95\% Cl, 2.0\%-3.8\%); $5.2 \%$ (4.0\%-6.4\%) presented with SVl, and 27.6\% (23.3\%$32.0 \%$ ) presented with MVl. Cataracts were the leading cause of blindness $(77.6 \%)$, followed by other posterior segment diseases $(6.0 \%)$ and nontrachomatous corneal opacity $(4.5 \%)$ (Table 2$)$. Cataracts were also the primary cause of SVl (79.4\%), while uncorrected refractive errors were the primary cause of $\mathrm{MVI}(67.9 \%)$.

In Guatemala, only $24.3 \%$ of all eyes that are blind (VA $<20 / 400)$ because of cataracts have been treated surgically; that is, only 2.4 of every 10 eyes with cataract-caused blindness. Of all individuals with bilateral blindness caused by cataracts, $29.5 \%$ (29.3\% of men and $29.6 \%$ of women) have had surgery on one eye (Table 3 ). In cases of visual impairment $<20 / 200$, the CSC of eyes was thus $13.7 \%$ and that of people was $17.4 \%$.

After cataract surgery, $42 \%$ of evaluated eyes had a VA of $20 / 60$ or better and $25.0 \%$ could not see at $20 / 200$ with available correction (Table 4). With the best correction, the results improved to $66.0 \%$ with a good outcome and $19.0 \%$ with a poor outcome. As expected, visual outcomes were better in eyes that had been operated on within 3 years before the study ( $82.9 \%$ good/ borderline and $17.1 \%$ poor) than in those that had been operated on within 4 to 6 years (65.3\% good/borderline, 
$34.6 \%$ poor) or 7 or more years $(74.4 \%$ good/borderline and $25.6 \%$ poor) before the study. Intraocular lenses were present in $91 \%$ of all operated eyes; $43.0 \%$ of the surgeries were conducted in voluntary or charity hospitals, $29 \%$ in private hospitals, and $28 \%$ in government hospitals. Uncorrected postoperative refractive errors (which included incorrectly powered intraocular lenses and surgically induced astigmatism) were the major cause of borderline/poor outcomes (57.1\%), followed by selection $(30.9 \%)$, sequelae $(28.6 \%)$, and surgery

Table 1. Adjusted results for all causes of blindness, SVI, and MVI, Guatemala, 2015

\begin{tabular}{|c|c|c|c|c|c|c|c|c|c|}
\hline & \multicolumn{3}{|c|}{ Males } & \multicolumn{3}{|c|}{ Females } & \multicolumn{3}{|c|}{ Total } \\
\hline & $n$ & $\%$ & $(95 \% \mathrm{Cl})$ & $n$ & $\%$ & $(95 \% \mathrm{Cl})$ & $n$ & $\%$ & $(95 \% \mathrm{Cl})$ \\
\hline \multicolumn{10}{|c|}{ Blindness (VA $<20 / 400$ in the better eye with best correction or pinhole) } \\
\hline All bilateral cases & 16,853 & 1.9 & $(0.8-3.1)$ & 31,074 & 3.2 & $(2.3-4.1)$ & 47,927 & 2.6 & $(1.8-3.4)$ \\
\hline All eyes & 84,147 & 4.8 & $(3.3-6.3)$ & 109,301 & 5.6 & $(4.5-6.7)$ & 193,448 & 5.2 & $(4.3-6.2)$ \\
\hline \multicolumn{10}{|c|}{ Blindness (VA <20/400 in the better eye with available correction [presenting VA]) } \\
\hline All bilateral cases & 18,426 & 2.1 & $(0.9-3.3)$ & 35,146 & 3.6 & $(2.6-4.6)$ & 53,572 & 2.9 & $(2.0-3.8)$ \\
\hline All eyes & 93,838 & 5.4 & $(3.8-6.9)$ & 118,871 & 6.1 & $(5.0-7.2)$ & 212,709 & 5.8 & $(4.7-6.8)$ \\
\hline \multicolumn{10}{|c|}{ SVI (VA <20/200-20/400 in the better eye with available correction) } \\
\hline All bilateral cases & 41,379 & 4.7 & $(3.3-6.1)$ & 54,881 & 5.6 & $(4.3-7.0)$ & 96,260 & 5.2 & $(4.0-6.4)$ \\
\hline All eyes & 94,571 & 5.4 & $(3.9-6.9)$ & 125,097 & 6.4 & $(5.2-7.7)$ & 219,668 & 5.9 & $(4.8-7.1)$ \\
\hline \multicolumn{10}{|c|}{ MVI (VA <20/60-20/200 in the better eye with available correction) } \\
\hline All bilateral cases & 236,239 & 27.0 & $(22.2-31.8)$ & 274,767 & 28.2 & $(23.7-32.7)$ & 511,006 & 27.6 & $(23.3-32.0)$ \\
\hline All eyes & 485,707 & 27.8 & $(23.3-32.3)$ & 572,563 & 29.4 & $(25.2-33.6)$ & $1,058,270$ & 28.6 & $(24.6-32.7)$ \\
\hline
\end{tabular}

$\mathrm{SVl}=$ severe visual impairment; $\mathrm{MVl}=$ moderate visual impairment; $\mathrm{EVl}=$ early visual impairment; $\mathrm{VA}=$ visual acuity; $\mathrm{Cl}=$ confidence interval.

Table 2. Principal causes of blindness, SVI, MVI, and EVI in persons (PVA)

\begin{tabular}{|c|c|c|c|c|c|c|}
\hline \multirow[b]{2}{*}{ Cause } & \multicolumn{2}{|c|}{ Blindness } & \multicolumn{2}{|c|}{ SVI } & \multicolumn{2}{|c|}{ MVI } \\
\hline & $n$ & $\%$ & $n$ & $\%$ & $n$ & $\%$ \\
\hline 1. Refractive error & 3 & $2.2 \%$ & 15 & $6.6 \%$ & 723 & $67.9 \%$ \\
\hline 2. Aphakia uncorrected & 0 & $0.0 \%$ & 0 & $0.0 \%$ & 0 & $0.0 \%$ \\
\hline 3. Cataract untreated & 104 & $77.6 \%$ & 181 & $79.4 \%$ & 278 & $26.1 \%$ \\
\hline 4. Cataract surgical complications & 3 & $1.1 \%$ & 2 & $0.9 \%$ & 2 & $0.2 \%$ \\
\hline 5. Trachomatous corneal opacity & 2 & $1.1 \%$ & 1 & $0.4 \%$ & 2 & $0.2 \%$ \\
\hline 6. Nontrachomatous corneal opacity & 6 & $4.6 \%$ & 8 & $3.5 \%$ & 20 & $1.9 \%$ \\
\hline 7. Phthisis & 0 & $0.0 \%$ & 0 & $0.0 \%$ & 0 & $0.0 \%$ \\
\hline 8. Onchocerciasis & 0 & $0.0 \%$ & 0 & $0.0 \%$ & 0 & $0.0 \%$ \\
\hline 9. Glaucoma & 3 & $2.3 \%$ & 5 & $2.2 \%$ & 10 & $0.9 \%$ \\
\hline 10. Diabetic retinopathy & 2 & $1.5 \%$ & 6 & $2.6 \%$ & 13 & $1.2 \%$ \\
\hline 11. AMD & 1 & $0.7 \%$ & 0 & $0.0 \%$ & 1 & $0.1 \%$ \\
\hline 12. Other posterior segment disease & 8 & $6.0 \%$ & 7 & $3.1 \%$ & 13 & $1.2 \%$ \\
\hline 13. All other globe/CNS abnormalities & 2 & $1.5 \%$ & 3 & $1.3 \%$ & 3 & $0.3 \%$ \\
\hline Total & 134 & $100.0 \%$ & 228 & $100.0 \%$ & 1,065 & $100.0 \%$ \\
\hline \multicolumn{7}{|c|}{ Blindness, SVI, and MVI in persons by intervention category } \\
\hline A. Treatable $(1,2,3)$ & 107 & $79.9 \%$ & 196 & $86.0 \%$ & 1,001 & $94.0 \%$ \\
\hline B. Preventable (PHC/PEC services) $(5,6,7,8)$ & 8 & $6.0 \%$ & 9 & $4.0 \%$ & 22 & $2.1 \%$ \\
\hline C. Preventable (ophthalmic services) $(4,9,10)$ & 8 & $6.0 \%$ & 13 & $5.7 \%$ & 25 & $2.4 \%$ \\
\hline D. Avoidable $(A+B+C)$ & 123 & $91.8 \%$ & 218 & $95.6 \%$ & 1,048 & $98.4 \%$ \\
\hline E. Posterior segment causes $(8,9,10,11,12)$ & 14 & $10.5 \%$ & 18 & $7.9 \%$ & 37 & $3.5 \%$ \\
\hline
\end{tabular}

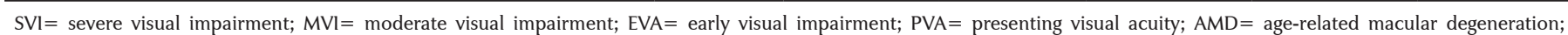
$\mathrm{CNS}=$ central nervous system; PHC/PEC. 
(21.4\%) (Table 5). Subjects with bilateral cataracts and a BCVA $<20 / 200$ said that cost was the main barrier to cataract surgery $(56.7 \%)$, followed by an unawareness of treatment (18.3\%).

\section{DISCUSSION}

This is the first nationwide population-based study of the prevalence and causes of blindness in Guatemala. The age- and sex-adjusted prevalence of blindness and visual impairment of $2.9 \%(95 \% \mathrm{Cl}, 2.0 \%-3.8 \%)$ was higher than the estimated values in other Central American countries, such as Costa Rica $(1.7 \%$; $95 \% \mathrm{Cl}$,

Table 3. Cataract surgical coverage, Guatemala, 2015

\begin{tabular}{lrrr}
\hline & Males & Females & Total \\
\hline Cataract surgical coverage (eyes) - percentage & & & \\
VA $<20 / 400$ & 21.6 & 25.8 & 24.3 \\
VA $<20 / 200$ & 11.3 & 15.3 & 13.7 \\
VA $<20 / 60$ & 5.5 & 8.4 & 7.2 \\
Cataract surgical coverage (persons) - percentage & & & \\
VA $<20 / 400$ & 29.3 & 29.6 & 29.5 \\
VA $<20 / 200$ & 14.4 & 19.1 & 17.4 \\
VA $<20 / 60$ & 7.1 & 10.5 & 9.1 \\
\hline VA= visual acuity. & & &
\end{tabular}

Table 4. Outcome after cataract surgery with available correction (eyes), Guatemala, 2015

\begin{tabular}{|c|c|c|c|c|c|c|}
\hline & \multicolumn{2}{|c|}{ Males } & \multicolumn{2}{|c|}{ Females } & \multicolumn{2}{|c|}{ Total } \\
\hline & $n$ & $\%$ & $n$ & $\%$ & $n$ & $\%$ \\
\hline Good: can see $20 / 60$ & 13 & $40.6 \%$ & 29 & $42.6 \%$ & 42 & $42.0 \%$ \\
\hline Borderline: can see $20 / 200$ & 13 & $40.6 \%$ & 20 & $29.4 \%$ & 33 & $33.0 \%$ \\
\hline Poor: cannot see $20 / 200$ & 6 & $18.8 \%$ & 19 & $27.9 \%$ & 25 & $25.0 \%$ \\
\hline Total & 32 & $100.0 \%$ & 68 & $100.0 \%$ & 100 & $100.0 \%$ \\
\hline
\end{tabular}

$1.2 \%-2.2 \%)^{(13)}$, El Salvador $(2.4 \% \text {; 95\% Cl, } 2.2 \%-2.6 \%)^{(14)}$, and Honduras $\left(1.9 \%\right.$; 95\% Cl, 1.4\%-2.4\%) ${ }^{(15)}$, and similar to that in Panama (3.0\%; 95\% Cl, 2.3\%-3.6\%) $)^{(16)}$. In consistency with the results of most population-based studies of blindness in Latin America, unoperated cataract was the primary cause of blindness ${ }^{(1,3)}$. Beltranena et al. previously highlighted the importance of unoperated cataracts as a cause of blindness in four Guatemalan provinces, but data from other regions were not available ${ }^{(8)}$.

Guatemala has one of the lowest percentages of elderly people among Latin American countries, and this helps to account for a lower prevalence of bilateral blindness caused by posterior pole diseases such as diabetic retinopathy and age-related macular degeneration compared with other Latin American countries and regions ${ }^{(3)}$, especially those with a different age structure, such as Uruguay ${ }^{(17)}$, Argentina ${ }^{(18)}$, and southeastern Bra$\mathrm{zil}^{(19,20)}$. Other variables not evaluated in this study include eating habits and differences in ethnic composition.

The estimated CSC in people with PVA $<20 / 400$ in this study is the lowest reported from studies in Latin America using the RAAB methodology in the last decade $^{(3)}$. Pongo-Aguila et al. in Piura, Northern Peru, in 2002 ${ }^{(21)}$, Duerksen et al. in Asunción, Paraguay, in 1999, ${ }^{(22)}$ and Beltranena et al. in Southern Guatemala in $2004^{(8)}$ all reported lower CSC rates than those in the present study, ranging from $23.1 \%$ to $38 \%$, and more recent studies in Peru and Paraguay have shown increased coverage of $66.9 \%$ and $90 \%^{(23,24)}$. In our study population, fewer than half of the participants with blindness caused by cataracts had received surgery. The low CSC also accounts for the importance of cataracts as a cause of MSI and SVI. The cataract surgery rate (CSR), the number of cataract surgeries performed per million population per year ${ }^{(25)}$, in Guatemala is one of the lowest in the region. It is below the target CSR, even for a country with a

Table 5. Causes of PVA <20/60 (good, borderline, and poor outcomes) after cataract surgery, Guatemala, 2015

\begin{tabular}{|c|c|c|c|c|c|c|c|c|c|c|}
\hline \multirow[b]{2}{*}{ Outcome } & \multicolumn{2}{|c|}{ Selection $^{\mathrm{a}}$} & \multicolumn{2}{|c|}{ Surgery ${ }^{b}$} & \multicolumn{2}{|c|}{ Spectacles $^{c}$} & \multicolumn{2}{|c|}{ Sequelae $^{d}$} & \multicolumn{2}{|c|}{ Can see $20 / 60$} \\
\hline & $n$ & $\%$ & $n$ & $\%$ & $n$ & $\%$ & $n$ & $\%$ & $n$ & $\%$ \\
\hline Good: can see $20 / 60$ & 0 & $0.0 \%$ & 0 & $0.0 \%$ & 0 & $0.0 \%$ & 0 & $0.0 \%$ & 42 & $100.0 \%$ \\
\hline Borderline: can see $20 / 200$ & 4 & $30.8 \%$ & 2 & $22.2 \%$ & 23 & $95.8 \%$ & 4 & $33.3 \%$ & 0 & $0.0 \%$ \\
\hline Poor: cannot see $20 / 200$ & 9 & $69.2 \%$ & 7 & $77.8 \%$ & 1 & $4.2 \%$ & 8 & $66.7 \%$ & 0 & $0.0 \%$ \\
\hline Total & 13 & $100.0 \%$ & 9 & $100.0 \%$ & 24 & $100.0 \%$ & 12 & $100.0 \%$ & 42 & $100.0 \%$ \\
\hline
\end{tabular}

PVA= presenting visual acuity.

${ }^{\mathrm{a}}=$ Patients selected for surgery had other pathologies causing visual impairment (e.g., glaucoma, age-related macular degeneration, diabetic retinopathy); ${ }^{\mathrm{b}}=$ Surgical complication or immediate postsurgical complication; ${ }^{\mathrm{c}}=$ Prescription not correcting postoperative refractory problem (e.g., astigmatism) or wrong power intraocular lens; ${ }^{\mathrm{d}}=$ Late postoperative complications (e.g., posterior capsule opacification). 
young age structure, and it decreased from 2005 to 2012 at a time when a majority of Latin American countries experienced an increase in $\mathrm{CSR}^{(26)}$.

Most subjects with cataract-caused blindness mentioned cost as a major barrier to cataract surgery, followed by an unawareness of possible treatment. Currently, voluntary and charity hospitals play an important role in cataract treatment in Guatemala, performing approximately 4 of every 10 cataract surgeries. Fewer than one-third of cataract surgeries were performed in public hospitals. The number and availability of ophthalmologists is an issue in Guatemala ${ }^{(7)}$. Not only is the number of ophthalmologists per capita considerably below the Latin American average, but they are highly concentrated in the wealthiest areas of the country. Since most cases of blindness can be prevented by increasing access to high-quality cataract surgery, we recommend implementation of national policies that encourage the creation of more residency services that focus on cataract surgery skills, especially in poorer areas. The visual outcomes reported in this study are worse than those reported in previous RAAB studies conducted in Central America $^{(3)} ; 42 \%$ of operated eyes had PVAs $\geq 20 / 60$, and there is still room for improvement to achieve WHO vision goals ${ }^{(27)}$. Since uncorrected postoperative refractive error was the leading cause of poor cataract surgery outcome, a comprehensive postoperative evaluation with provision of spectacles would improve outcomes in a significant proportion of individuals.

The study limitations include not estimating the prevalence of childhood blindness, but that was not possible because the RAAB methodology does not include those $<50$ years of age. Also, near vision impairment was not assessed. Ramke et al. ${ }^{(28)}$ recently developed a novel indicator to assess CSC and good visual outcome after cataract surgery. Effective cataract surgical coverage $(\mathrm{eCSC})$ is an indicator of the level of care, using BCVA $<20 / 200$ as a cutoff to determine coverage and VA $>20 / 60$ as the definition of good outcome, following $\mathrm{WHO}$ recommendations ${ }^{(28)}$. Considering the $\mathrm{WHO}$ outcome and coverage targets, Ramke et al. defined eCSC $\geq 90$ as excellent, 80-89 as very good, 70-79 as good, and 60-69 as satisfactory. The eCSC (VA <3/60) for Guatemala is $12.3 \%$, meaning that of all people with bilateral cataracts and $\mathrm{BCVA}<20 / 400$ in the better eye, $12.3 \%$ had surgery in one or both eyes and had a presenting VA of $20 / 60$ or better in the better eye. This rate is considered low. As expected, uncorrected refractive errors were the leading cause of MVI (67.9\%) in this survey; a similar trend was observed in other population-based studies in Latin America.

To conclude, the availability of high-quality, affordable cataract surgery for visually impaired and blind people is a public health priority in Guatemala. Affordable cataract surgery should be provided not only in the wealthiest areas of the country, but also in poor rural communities. The number of ophthalmologists in Guatemala is considered low, and cataract is the leading cause of blindness. We recommend the creation of more residency programs with appropriate cataract surgery training. It is important to note that life expectancy at birth in Guatemala is expected to increase from 72 years in 2015 to 79 years in 2050. The number of individuals $>50$ years of age will more than triple by then ${ }^{(6)}$, leading to an increased need for cataract surgery and treatment of other sight-threatening conditions. Finally, as cost is a major barrier for cataract surgery, manual, small-incision surgery, which is less expensive than phacoemulsification and has comparable outcomes, is an alternative ${ }^{(29)}$. It is already available in some institutions in Latin America ${ }^{(30)}$ and might be a good alternative for those Guatemalans in need.

\section{REFERENCES}

1. Furtado JM, Lansingh VC, Carter M), et al. Causes of blindness and visual impairment in Latin America. Surv Ophthalmol. 2012; 57(2):149-77.

2. Leasher JL, Lansingh V, Flaxman SR, et al. Prevalence and causes of vision loss in Latin America and the Caribbean: 1990-2010. Br J Ophthalmol. 2014;98(5):619-28.

3. Silva JC, Mujica OJ, Vega E, et al. A comparative assessment of avoidable blindness and visual impairment in seven Latin American countries: prevalence, coverage, and inequality. Rev Panam Salud Publica. 2015;37(1):13-20.

4. Instituto Nacional de Estadística de Guatemala. Caracterización de la República de Guatemala. https://www.ine.gob.gt/sistema/uploads/ 2014/02/26/L5pNHMXzxy5FFWmk9NHCrK9x7E5Qqvvy.pdf

5. The World Bank. Population. http://data.worldbank.org/country/ guatemala Accessed 25/08/2017.

6. United States Census Bureau. Demographic Overview Guatemala. http://www.census.gov/population/international/ data/idb/region.php? $\mathrm{N}=\% 20$ Results $\% 20 \& \mathrm{~T}=13 \& \mathrm{~A}=$ separate $\& R T=0 \& Y=2030 \& R=-1 \& C=G T$ Accessed 09/01/2017.

7. Hong H, Mujica OJ, Anaya J, Lansingh VC, Lopez E, Silva JC. The Challenge of Universal Eye Health in Latin America: distributive inequality of ophthalmologists in 14 countries. BMJ Open. 2016; 6(11):e012819.

8. Beltranena F, Casasola K, Silva JC, Limburg H. Cataract blindness in 4 regions of Guatemala: results of a population-based survey. Ophthalmology. 2007;114(8):1558-63.

9. Silva JC, Diaz MA, Maul E, Munoz BE, West SK. Population-Based Study of Trachoma in Guatemala. Ophthalmic Epidemiol. 2015; 22(3):231-6 
10. Pan American Health Organization. Guatemala is the fourth country in the world to eliminate onchocerciasis, known as 'river blindness'. http://www.paho.org/hq/index.php?option=com_con tent $\&$ view $=$ article $\& i d=12520 \% 3$ Aguatemala-eliminates-onchocerciasis-river-blindness\&ltemid=135\&lang=en 2017.

11. Kuper H, Polack S, Limburg H. Rapid assessment of avoidable blindness. Community Eye Health. 2006;19(60):68-9.

12. Limburg H, Foster A. CATARACT SURGICAL COVERAGE: An indicator to measure the impact of cataract intervention programmes. Community Eye Health. 1998;11(25):3-6.

13. Castellón RA, Vargas EC, Chhavarría RC, Vargas GR. Estimación de la prevalencia de enfermedades asociadas a ceguera prevenible y discapacidad visual- Costa Rica 2015. Vol 1. San José, Costa Rica: Editorial Nacional de Salud y Seguridad Social- Caja Costarricense de Seguro Social; 2016.

14. Rius A, Guisasola L, Sabido M, et al. Prevalence of visual impairment in El Salvador: inequalities in educational level and occupational status. Rev Panam Salud Publica. 2014;36(5):290-9.

15. Alvarado D, Rivera B, Lagos L, et al. [National survey of blindness and avoidable visual impairment in Honduras]. Rev Panam Salud Publica. 2014;36(5):300-5.

16. Lopez M, Brea l, Yee R, et al. [Survey on avoidable blindness and visual impairment in Panama]. Rev Panam Salud Publica. 2014; 36(6):355-60.

17. Gallarreta M, Furtado JM, Lansingh VC, Silva JC, Limburg H. Rapid assessment of avoidable blindness in Uruguay: results of a nationwide survey. Rev Panam Salud Publica. 2014;36(4):219-24.

18. Barrenechea R, de la Fuente I, Plaza RG, et al. [National survey of blindness and avoidable visual impairment in Argentina, 2013]. Rev Panam Salud Publica. 2015;37(1):7-12.

19. Arieta CE, de Oliveira DF, Lupinacci AP, et al. Cataract remains an important cause of blindness in Campinas, Brazil. Ophthalmic Epidemiol. 2009;16(1):58-63.
20. Salomao SR, Cinoto RW, Berezovsky A, et al. Prevalence and causes of vision impairment and blindness in older adults in Brazil: the Sao Paulo Eye Study. Ophthalmic Epidemiol. 2008;15(3):167-75.

21. Pongo Aguila L, Carrion R, Luna W, Silva JC, Limburg H. [Cataract blindness in people 50 years old or older in a semirural area of northern Peru]. Rev Panam Salud Publica. 2005;17(5-6):387-93.

22. Duerksen R, Limburg H, Carron JE, Foster A. Cataract blindness in Paraguay-results of a national survey. Ophthalmic Epidemiol. 2003;10(5):349-57.

23. Duerksen R, Limburg H, Lansingh VC, Silva JC. Review of blindness and visual impairment in Paraguay: changes between 1999 and 2011. Ophthalmic Epidemiol. 2013;20(5):301-7.

24. Campos B, Cerrate A, Montjoy E, et al. [National survey on the prevalence and causes of blindness in Peru]. Rev Panam Salud Publica. 2014;36(5):283-9.

25. Lansingh VC, Resnikoff S, Tingley-Kelley K, et al. Cataract surgery rates in latin america: a four-year longitudinal study of 19 countries. Ophthalmic Epidemiol. 2010;17(2):75-81.

26. Batlle JF, Lansingh VC, Silva JC, Eckert KA, Resnikoff S. The cataract situation in Latin America: barriers to cataract surgery. Am J Ophthalmol. 2014;158(2):242-250 e241.

27. Walia T, Yorston D. Improving surgical outcomes. Community Eye Health. 2008;21(68):58-9.

28. Ramke J, Gilbert CE, Lee AC, Ackland P, Limburg H, Foster A. Effective cataract surgical coverage: An indicator for measuring quality-of-care in the context of Universal Health Coverage. PLoS One. 2017;12(3):e0172342.

29. Gogate PM, Kulkarni SR, Krishnaiah S, et al. Safety and efficacy of phacoemulsification compared with manual small-incision cataract surgery by a randomized controlled clinical trial: six-week results. Ophthalmology. 2005;112(5):869-74.

30. Congdon N, Yan X, Lansingh V, et al. Assessment of cataract surgical outcomes in settings where follow-up is poor: PRECOG, a multicentre observational study. Lancet Glob Health. 2013;1(1):e37-45. 